\title{
Detection of mixed clarithromycin-resistant and -susceptible Helicobacter pylori using nested PCR and direct sequencing of DNA extracted from faeces
}

Correspondence

Norihisa Noguchi

noguchin@ps.toyaku.ac.jp

Received 22 March 2007

Accepted 19 May 2007

\author{
Norihisa Noguchi, ${ }_{1}^{1}$ Emiko Rimbara, ${ }_{1}^{1}$ Ayami Kato, ${ }^{1}$ Akifumi Tanaka, ${ }^{2}$ \\ Kengo Tokunaga, ${ }^{2}$ Takashi Kawai, ${ }^{3}$ Shin'ichi Takahashi ${ }^{2}$ \\ and Masanori Sasatsu ${ }^{1}$
}
${ }^{1}$ Department of Microbiology, School of Pharmacy, Tokyo University of Pharmacy and Life Science, 1432-1 Horinouchi, Hachioji, Tokyo 192-0392, Japan
${ }^{2}$ Third Department of Internal Medicine, Kyorin University School of Medicine, 6-20-2 Shinkawa, Mitaka, Tokyo 181-8611, Japan
${ }^{3}$ Endoscopy Center, Tokyo Medical University, 6-7-1 Nishishinjuku, Shinjuku, Tokyo 160-0023, Japan

\begin{abstract}
The major cause of chemotherapy failure in patients with chronic gastritis and peptic ulcers caused by Helicobacter pylori is clarithromycin (CAM) resistance due to a mutation in the $23 S$ rRNA gene. This study describes a non-invasive and accurate method for the detection of mixed CAM-resistant and -susceptible $H$. pylori by sequencing of the $H$. pylori 23S rRNA gene.

Faeces were crushed with beads and the 23S rRNA gene was amplified using a nested PCR on the extracted DNA. Mutation analysis of this gene using this method showed that $20.4 \%$ of patients carried mixed CAM-susceptible (wild type) and -resistant (A2142G or A2143G mutant) H. pylori. Furthermore, it was found that $66.6 \%$ of patients who had been treated unsuccessfully carried one of these mutations in the 23S rRNA gene (including the mixed type), whilst standard culture detected CAM-resistant isolates in only $22.2 \%$ of patients with unsuccessful treatment. These data suggest that, for successful therapy, the diagnosis method described here would more accurately detect CAM-resistant $H$. pylori, including mixed infections.
\end{abstract}

\section{INTRODUCTION}

Helicobacter pylori is a Gram-negative, spiral bacterium found in the human stomach. This micro-organism causes chronic gastritis and peptic ulcers (Kuipers, 1997) and is linked to gastric cancer and other non-gastrointestinal diseases (Kusters et al., 2006; Leong \& Sung, 2002). To treat H. pylori infections, a triple therapy is used comprising a combination of a proton pump inhibitor and two antimicrobial agents. This is reported to be the most successful method for eradication of infection (Malfertheiner et al., 2002). In Japan, a combination of lansoprazole, amoxicillin and clarithromycin (CAM) (the LAC regimen) is commonly used to eliminate $H$. pylori (Asaka et al., 2001). Although most patients are treated successfully with this triple therapy, some failure has necessitated the use of additional drugs such as levofloxacin (Asaka et al., 2001; Kato et al., 2000). The major cause of therapy failure in patients is resistance to CAM (Kato et al., 2000; Rimbara et al., 2005a). Therefore, a reliable

Abbreviations: CAM, clarithromycin; HpSA, H. pylori stool antigen. diagnostic test to detect macrolide resistance would be useful in planning a therapeutic regimen. Standard culture is generally used to determine the susceptibility of $H$. pylori to antimicrobial agents; however, acquiring a test sample is invasive for the patient, as endoscopy is required to obtain gastric specimens. Faecal culture is not possible, as $\mathrm{H}$. pylori coccoid forms are unculturable; however, there are some reliable non-invasive tests for the diagnosis of $H$. pylori infections (Graham et al., 1987; Leodolter et al., 2003; Shuber et al., 2002; Vaira et al., 1999).

Resistance to CAM in $H$. pylori is due to a mutation in the $23 \mathrm{~S}$ rRNA subunit in the $50 \mathrm{~S}$ ribosome. The two most common mutations are an adenine-to-guanine transition at position 2142 or 2143 , the latter leading to an adenineto-cytosine transversion at position 2142 (Alarcon et al., 2003; van Doorn et al., 2001). Resistance due to mutations at other positions has also been reported (Fontana et al., 2002; Khan et al., 2004; Toracchio et al., 2004). Several methods to detect CAM-resistant $H$. pylori from faecal samples have used RFLP (Alarcon et al., 2003), real-time PCR (Schabereiter-Gurtner et al., 2004) or other methods 
(Morris et al., 2005; Prokhorenko et al., 2006; van Doorn et al., 2001).

In the above methods, it is important that the DNA of all of the micro-organisms in the faeces is isolated efficiently. H. pylori converts from a spiral shape in the stomach to a coccoid form in the faeces, which is unculturable in vitro (Kusters et al., 1997; Thomas et al., 1992). Therefore, isolation of CAM-resistant $H$. pylori using coccoid-form DNA from faeces is required for mutation analysis of the $23 \mathrm{~S}$ rRNA gene of $H$. pylori.

Here, we developed an improved method to extract DNA from faeces together with an efficient and inexpensive PCR procedure. Previously, we reported a method for extracting bacterial DNA, including that of $H$. pylori, from faeces using a combination of enzymic lysis and crushing with beads. To diagnose CAM-resistant $H$. pylori infection, we detected mutations in the $H$. pylori $23 \mathrm{~S}$ rRNA gene with DNA specifically amplified using a nested PCR (Rimbara et al., 2005b). Chemical cell lysis including enzyme treatment and physical crushing are generally used as methods for extracting DNA from cells (Akiyama et al., 2005). Chemical lysis is a simple method and is used in commercial kits (McOrist et al., 2002; Monteiro et al., 2001). Compared with chemical lysis, physical crushing is able to isolate DNA uniformly from various species and different cell types (seeds, Gram-positive bacteria and spores), although a special homogenizer or grinder is necessary (Akiyama et al., 2005; Matsuki et al., 2004). Previously used methods needed improvement as the procedures were complicated and time-consuming, such as the long incubation times required for enzymic reactions. Furthermore, the nested PCR in our previous study required about $4 \mathrm{~h}$ for amplification using DNA polymerase. Therefore, in this study, we improved our previous method for detection of mutations in the $H$. pylori $23 \mathrm{~S}$ rRNA gene from faeces and compared this improved method with the $H$. pylori stool antigen (HpSA) ELISA and culture methods. We also correlated our results with data from patients using the triple therapy to help design a more successful treatment for patients using the LAC regimen.

\section{METHODS}

Patients and materials. A total of 146 stool specimens was obtained from 18 healthy subjects ( 12 males and 6 females; mean age $22.9 \pm 1.4$ years, range 22-26 years) and 128 patients (101 males and 27 females; mean age $51.5 \pm 14.8$ years, range $20-81$ years) who visited Tokyo Medical University Hospital, Tokyo, Japan, or Kyorin University Hospital, Tokyo, Japan, between 1998 and 2004. Diagnoses were made in patients having gastric cancer $(n=25)$, peptic ulcers $(n=82)$, chronic gastritis $(n=19)$, gastric polyps $(n=1)$ and oesophageal cancer $(n=1)$. Faeces taken from all patients and healthy subjects were stored at $-80{ }^{\circ} \mathrm{C}$ until used. Upper endoscopy procedures were performed on 114 patients and gastric specimens from the antrum or body were used for $H$. pylori culture. Informed consent was obtained from all patients and healthy subjects.

HpSA ELISA. An enzyme immunoassay to detect $H$. pylori antigen in stool specimens was performed using a Premier Platinum HpSA kit (Meridian Diagnostics) as reported previously (Vaira et al., 1999). Measuring the absorbance at $450 / 630 \mathrm{~nm}$, the cut-off levels for the HpSA test were $<0.100$ for a negative result, $0.100<A_{450 / 630}<0.120$ as equivocal and $>0.120$ for a positive result, as recommended by the manufacturer.

DNA extraction from faeces. DNA was extracted from faeces using a bead crushing method developed in this study. The tube contained $250 \mathrm{mg}$ silica powder $(63-210 \mu \mathrm{m}), 32.5 \mathrm{mg}$ ceramic beads $(1-2 \mathrm{~mm}$ diameter) and $75 \mathrm{mg}$ glass beads. Approximately $50 \mathrm{mg}$ faeces was added to the tube with $980 \mu \mathrm{l}$ sodium phosphate buffer and $180 \mu \mathrm{l} 7.5 \mathrm{M}$ guanidine solution containing $5 \%$ sarcosine and homogenized for $20 \mathrm{~s}$ at level 6 using a FastPrep FP120 instrument (Qbiogene). The homogenized solution was centrifuged at $14000 \mathrm{~g}$ for $30 \mathrm{~s}$. The supernatant was transferred into a new tube and $250 \mu \mathrm{l}$ of $3.5 \mathrm{M}$ sodium acetate ( $\mathrm{pH} 5.2$ ) was added. After mixing, the solution was centrifuged at $14000 \mathrm{~g}$ for $5 \mathrm{~min}$ and $350 \mu \mathrm{l}$ of the supernatant was purified using Wizard SV Gel and PCR Clean-up systems (Promega). The final volume for each DNA preparation was $50 \mu \mathrm{l}$.

\footnotetext{
Nested PCR of the $\boldsymbol{H}$. pylori 235 rRNA gene. Nested PCR for detection of mutations in the $H$. pylori $23 \mathrm{~S}$ rRNA gene was performed using the primers shown in Table 1. PCR primers were designed using regions with little sequence similarity to other bacterial species. Nested PCR was performed in a thermal cycler using Ex Taq (Takara Biomedicals) and PCR master mix (Promega) for the first and second PCRs, respectively. The conditions for the first PCR were as follows: initial denaturation at $95{ }^{\circ} \mathrm{C}$ for $2 \mathrm{~min}$; five cycles of $94{ }^{\circ} \mathrm{C}$ for $30 \mathrm{~s}$, $57{ }^{\circ} \mathrm{C}$ for $30 \mathrm{~s}$ and $72{ }^{\circ} \mathrm{C}$ for $30 \mathrm{~s}$; and 30 cycles of $94{ }^{\circ} \mathrm{C}$ for $15 \mathrm{~s}$, $57{ }^{\circ} \mathrm{C}$ for $15 \mathrm{~s}, 72{ }^{\circ} \mathrm{C}$ for $20 \mathrm{~s}$. A second PCR was performed using
}

Table 1. Primers used for nested PCR of the $H$. pylori $23 S$ rRNA gene

Primer positions are shown relative to the 23S rRNA gene sequence of $H$. pylori strain 26695.

\begin{tabular}{|llccc|}
\hline Primer & \multicolumn{1}{c|}{ Sequence $\left(\mathbf{5}^{\prime} \rightarrow \mathbf{3}^{\prime}\right)$} & $\boldsymbol{T}_{\mathbf{m}}\left({ }^{\circ} \mathbf{C}\right)$ & Position $(\mathbf{n t})$ & Amplicon (bp) \\
\hline First-round & & & & \\
Hp23S 1835F & GGTCTCAGCAAAGAGTCCCT & 62.4 & $1835-1854$ & 493 \\
Hp23S 2327R & CCCACCAAGCATTGTCCT & 63.6 & $2327-2310$ & \\
Second-round & & & & \\
Hp23S 1942F & AGGATGCGTCAGTCGCAAGAT & 68.2 & $1942-1962$ & 367 \\
Hp23S 2308R & CCTGTGGATAACACAGGCCAGT & 67.1 & $2308-2287$ & \\
\hline
\end{tabular}


$2 \mu \mathrm{l}$ of the first PCR product with initial denaturation at $95{ }^{\circ} \mathrm{C}$ for $2 \mathrm{~min}$, followed by 25 cycles of $94{ }^{\circ} \mathrm{C}$ for $10 \mathrm{~s}$ and $63{ }^{\circ} \mathrm{C}$ for $20 \mathrm{~s}$. The size of final PCR products was confirmed by electrophoresis in $2.5 \%$ agarose gels. DNA sequencing was performed using an ABI PRISM 3100 DNA sequencer (Applied Biosystems) with a BigDye Terminator version 3.1 cycle sequencing kit (Applied Biosystems). The primers Hp23S 1942F and Hp23S 2308R were used for DNA sequencing (Table 1).

H. pylori culture and antibiotic susceptibility testing. Gastric biopsy specimens obtained from 114 patients were cultured on modified Skirrow agar (Nissui Pharmaceutical) under microaerophilic conditions $\left(5 \% \mathrm{O}_{2}, 10 \% \mathrm{CO}_{2}\right.$ and $\left.85 \% \mathrm{~N}_{2}\right)$ for approximately 7 days at $37{ }^{\circ} \mathrm{C}$ (Rimbara et al., 2005a). H. pylori was identified using oxidase production and the API Campy test (bioMérieux). The isolates were stored in $20 \%$ glycerol/brain heart infusion broth at $-80{ }^{\circ} \mathrm{C}$ until used for the antibiotic susceptibility test. For $H$. pylori isolated prior to 2001, susceptibility to CAM was tested using the Dry Plate test (Eiken Chemical), as reported previously (Hoshiya et al., 2000), and an agar dilution method was used thereafter according to the Clinical and Laboratory Standards Institute, as reported previously (CLSI, 2002; Rimbara et al., 2005a). H. pylori isolates were considered resistant when the MIC for CAM was $\geqslant 1 \mu \mathrm{g} \mathrm{ml}$ (CLSI, 2002).

\section{RESULTS}

\section{Detection of $\boldsymbol{H}$. pylori infection from faeces using nested PCR and HpSA ELISA and from gastric specimens by culture}

Nested PCR and HpSA ELISA tests for the detection of H. pylori from faeces were performed on 146 samples taken from 128 patients and 18 healthy subjects. H. pylori was detected in 118/146 samples $(80.8 \%)$ from 116 patients and two healthy subjects using nested PCR, and in $122 / 124$ samples (84.9\%) from 122 patients and two healthy subjects using HpSA ELISA. Of the 124 samples with positive results using HpSA ELISA, eight were found to be negative using nested PCR, and two samples with negative results using HpSA ELISA were found to be positive using nested PCR. Thus, the detection sensitivity and specificity of the nested PCR method compared with the HpSA ELISA were 93.5 and $90.9 \%$, respectively.

Detection of $H$. pylori by culture was performed for 114 patients and compared with the results from the nested PCR and HpSA ELISA (Table 2). Using nested PCR, $H$. pylori was detected in $92.5 \%(99 / 107)$ of the patients with positive results by both HpSA ELISA and culture. All patients with positive results using either HpSA or culture were found to be positive using nested PCR. Of the eight patients with false-negative faecal samples using nested PCR, seven of the samples were collected before 2000 and more than 5 years before the DNA extraction. Furthermore, the amount of faeces was insufficient for the extraction of DNA in three of the eight patients. $H$. pylori was detected in one of the patients with negative results by both HpSA ELISA and culture, and was positive using the ${ }^{13} \mathrm{C}$-urea breath test.
Table 2. Detection of $H$. pylori from faeces by nested PCR and HpSA ELISA and from gastric biopsies by culture

Values are numbers of patients.

\begin{tabular}{|llccr|}
\hline \multirow{2}{*}{$\begin{array}{l}\text { ELSA } \\
\text { ELISA }\end{array}$} & Culture & \multicolumn{3}{c|}{ Nested PCR result } \\
\cline { 3 - 5 } & & Positive & Negative & Total \\
\hline Positive & Positive & 99 & 8 & 107 \\
Negative & Positive & 1 & 0 & 1 \\
Positive & Negative & 3 & 0 & 3 \\
Negative & Negative & $1^{*}$ & 2 & 3 \\
Total & & 104 & 10 & 114 \\
\hline
\end{tabular}

${ }^{\star}$ H. pylori infection was confirmed by ${ }^{13} \mathrm{C}$-urea breath test.

\section{Comparison of 23S rRNA gene mutants from faeces with susceptibility to CAM}

Of 100 patients with positive results by both culture and nested PCR, H. pylori culture isolates from two patients could not be tested for their susceptibilities to CAM due to poor growth. Therefore, the comparison of mutations of the $H$. pylori $23 \mathrm{~S}$ rRNA gene detected by nested PCR from faeces with the susceptibility of $H$. pylori culture isolates to CAM was performed in 98 patients. The results of DNA sequencing of the $H$. pylori $23 S$ rRNA gene amplified by nested PCR using DNA from faeces are shown in Table 3. The $23 \mathrm{~S}$ rRNA gene without mutation (wild type) was detected in 58/98 patients $(59.2 \%)$. The $23 \mathrm{~S}$ rRNA gene with an A2142G or A2143G mutation was detected in nine $(9.2 \%)$ and $31(31.6 \%)$ patients, respectively. Of the nine patients infected with $H$. pylori with the A2142G mutation, seven had a mixed-type infection, being simultaneously infected with the wild type (A2142G/wild type). Similarly, a mixed-type infection comprising both the A2143G mutation and wild type (A2143G/wild type) was detected in 13 of the 31 patients with the $23 \mathrm{~S}$ rRNA gene mutation A2143G.

A comparison of the presence of a mutation in the H. pylori $23 \mathrm{~S}$ rRNA gene from faeces with the susceptibility of $H$. pylori isolates to CAM is shown in Fig. 1. In 81 patients with CAM-susceptible H. pylori isolates, the mutation

Table 3. Mutations in the 23S rRNA gene of $H$. pylori in faeces from $98 \mathrm{H}$. pylori-infected patients

Values in parentheses are numbers of patients in which both wild type and mutant (A2142G or A2143G) 23S RNA genes were detected simultaneously.

\begin{tabular}{|lc|}
\hline Gene sequence & Number of patients \\
\hline Wild type & 58 \\
A2142G & $9(7)$ \\
A2143G & $31(13)$ \\
\hline
\end{tabular}




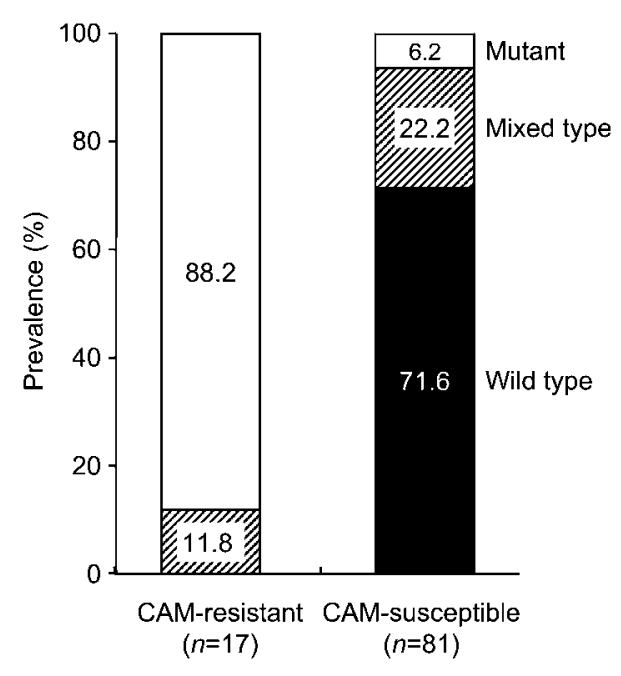

Fig. 1. Comparison of mutations in the $H$. pylori $23 S$ rRNA gene isolated from faeces with CAM susceptibility of $H$. pylori isolates. Mixed type indicates that both wild type and mutant (A2142G or A2143G) 23S RNA genes were detected simultaneously in these patients. The total number of patients is shown in parentheses.

(A2142G or A2143G) and mixed-type infection were detected in five $(6.2 \%)$ and $18(22.2 \%)$ patients, respectively; thus, overall the mutation was detected in 23 of the patients $(28.4 \%)$ with CAM-susceptible $H$. pylori isolates. Conversely, the wild type alone was not detected in 17 patients with CAM-resistant H. pylori isolates, but mixed-type infection was detected in two of these patients $(11.8 \%)$

\section{Correlation between successful therapy and detection of the resistant mutant $H$. pylori $23 S$ rRNA gene from faeces}

In a total of 128 patients who had had no previous therapy, 49 patients were treated with an LAC regimen consisting of $30 \mathrm{mg}$ lansoprazole, $750 \mathrm{mg}$ amoxicillin and $400 \mathrm{mg}$ CAM, each given twice daily for 7 days. This regimen is generally used for $H$. pylori eradication chemotherapy in Japan. Of the 49 patients, $40(81.6 \%)$ were treated successfully, whilst in nine $(18.4 \%)$ the treatment was unsuccessful. Fig. 2 shows the susceptibility to CAM and the mutations in the $23 \mathrm{~S}$ rRNA gene from faecal samples among the patients treated with the LAC regimen. Of the 40 patients treated successfully, CAM-resistant $H$. pylori culture isolates were detected in two patients (5.0\%), and a mutation (A2142G, A2143G or mixed type) in the H. pylori $23 \mathrm{~S}$ rRNA gene was detected in faecal samples from ten patients $(25.0 \%)$. Similarly, CAM-resistant $H$. pylori culture isolates were detected in two of the nine patients $(22.2 \%)$ in whom treatment was unsuccessful, whereas the mutated $H$. pylori $23 \mathrm{~S}$ rRNA gene was detected in faecal samples from six of the nine patients $(66.6 \%)$.

\section{DISCUSSION}

In this study, we developed an improved method to detect CAM-resistant $H$. pylori from faeces and compared our method with HpSA ELISA and culture methods using 146 faecal samples.

We previously reported a method for the extraction of DNA from faeces using a combination of enzymic lysis and physical crushing of the faeces (Rimbara et al., 2005b). In

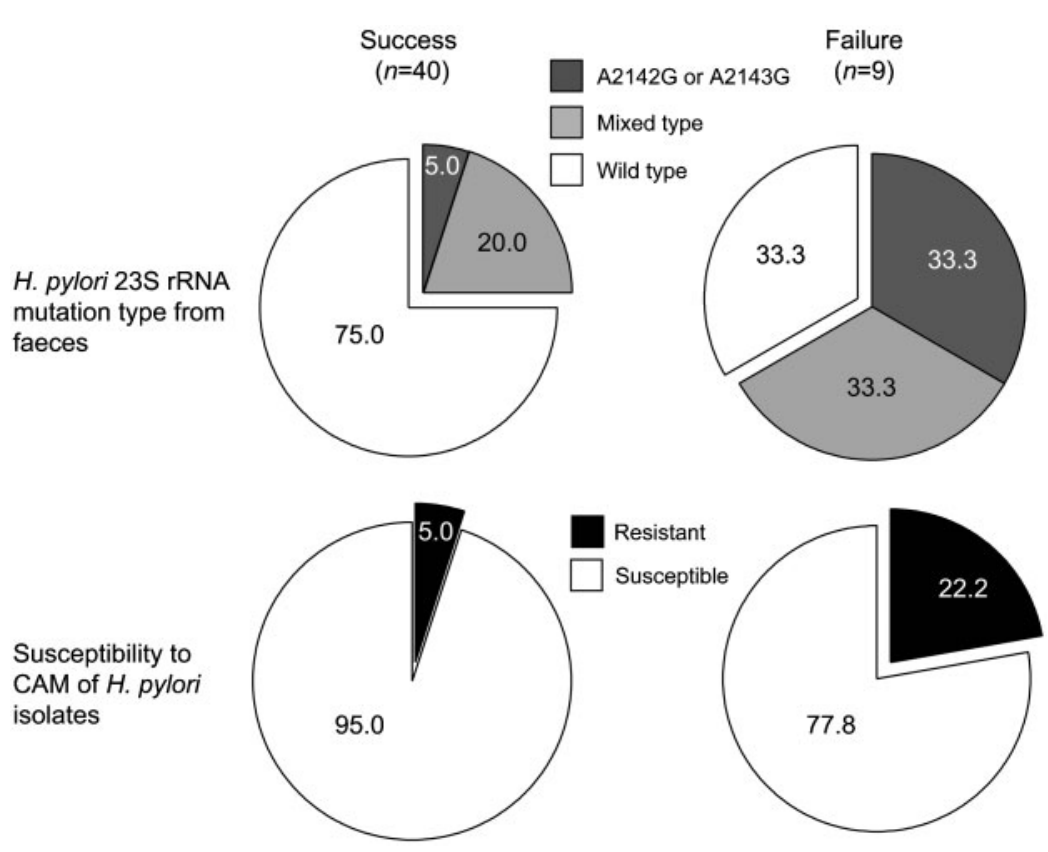

Fig. 2. Analysis of mutations in the $23 S$ rRNA gene isolated from faeces and susceptibility to CAM among patients treated using the LAC regimen. Values are percentages. See Fig. 1 legend for explanation of mixed-type infection. 
this study, we improved the composition of the beads and lysis buffer and omitted the enzymic incubation for cell lysis used in our previous method. This resulted in a more efficient and simpler method for isolation of DNA from the coccoid $H$. pylori cells in faeces. Furthermore, by reducing the amplification time for the first PCR in the nested PCR, we improved the efficiency of the nested PCR and were able to use a less expensive DNA polymerase. Generally, $H$. pylori DNA is extracted from faeces by chemical cell lysis using a commercial kit (Booka et al., 2005; Fontana et al., 2003). Compared with the commercial chemical cell lysis kit method, our improved method was able to extract DNA efficiently from a small amount of faeces and to amplify the $23 \mathrm{~S}$ rRNA gene of $H$. pylori with greater sensitivity than the commercial kit (Fig. 3). Therefore, this method, which efficiently crushed the $H$. pylori coccoid form to yield detectable DNA, may be useful for the isolation of bacterial DNA, including that of $H$. pylori, from faeces.

Although many methods for the diagnosis of $H$. pylori infections have been reported, including culture (Goodwin et al., 1985), the ${ }^{13} \mathrm{C}$-urea breath test (Graham et al., 1987) and HpSA ELISA (Vaira et al., 1999), a combination of two methods is recommended for a more reliable diagnosis (Ito

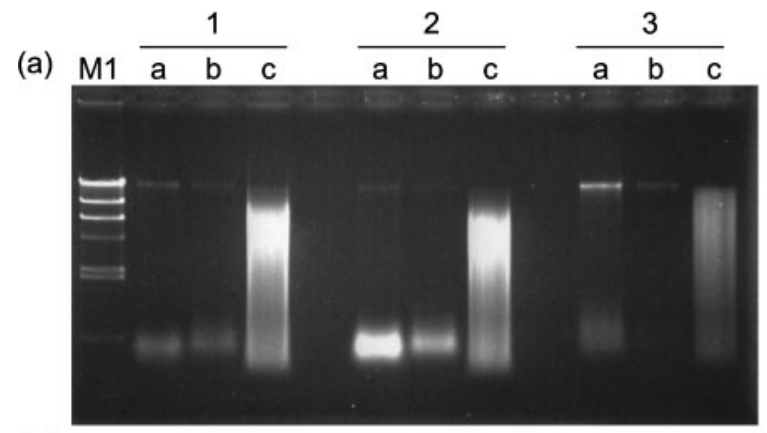

(b) $\mathrm{M} 2$

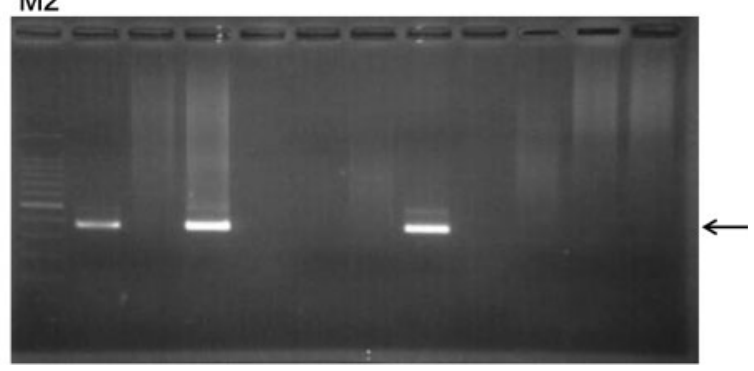

Fig. 3. Comparison of methods for the isolation of DNA from faeces in H. pylori-positive (1 and 2) and -negative (3) samples. (a) Electrophoresis of DNA isolated from faeces (1\% agarose gel). Lane M1, Hindlll-digested $\lambda$ DNA; lanes $a$ and b, DNA isolated from 200 and $50 \mathrm{mg}$ faeces, respectively, using a QIAamp DNA Stool Mini kit; lanes c, DNA isolated from $50 \mathrm{mg}$ faeces using the method developed in this study. (b) Agarose gel (2.5\%) electrophoresis of the nested PCR $H$. pylori 23S rRNA gene amplification product (arrow) from DNA isolated as described in (a). Lane M2, 100 bp DNA ladder. et al., 2005; Nurgalieva et al., 2006). To reduce the inconvenience for patients, we recommend non-invasive methods for the diagnosis of $H$. pylori infection. We found that the method developed in this study was able to detect CAM-resistant $H$. pylori in a non-invasive way with a sensitivity and specificity equal to HpSA ELISA and the invasive culture method.

It was also shown that false-negative results using the nested PCR were the result of the faecal samples containing a significant amount of moisture or fibre, or of an insufficient amount of faeces. We found that the false negatives could be resolved by replacement with another sample from the same patient (data not shown). Therefore, it is possible to select a successful therapy for the eradication of $H$. pylori using the method developed here.

For rapid detection of the mutation in the 23S rRNA gene, we performed a PCR-RFLP assay using MboII and BsaII (data not shown). Whilst a simple mutation of either A2142G or A2143G could be detected, it was difficult to demonstrate clear restriction patterns in the case of mixed infections. In the diagnosis of CAM resistance in H. pylori, accuracy is more important than rapidity, as the progress of $H$. pylori infection is gradual. Therefore, we detected the mutation in the 23S rRNA gene by DNA sequencing.

It was shown that mixed infections with both CAMsusceptible and -resistant $H$. pylori occurred in individual patients. We reported previously using culture that $39 \%$ of patients with CAM-resistant $H$. pylori were infected with both CAM-resistant and -susceptible H. pylori (Rimbara et al., 2005a). Wong et al. (2001) also report a high prevalence of mixed infections with metronidazole-resistant and -susceptible strains using culture. This indicates the need to test for the susceptibility of H. pylori isolates using more than two gastric specimens obtained from different sites in the stomach of a single patient to diagnose the presence of CAM-resistant $H$. pylori correctly. We showed that mixed infections could be detected noninvasively using the method developed here. SchabereiterGurtner et al. (2004) also reported mixed infections with CAM-susceptible and -resistant $H$. pylori in $4.4 \%$ of patients $(2 / 45)$ using a real-time PCR assay from faeces. In this study, a mixed-type infection was detected in 20/98 patients $(20.4 \%)$. These data strongly suggest that our method may detect mixed infections with high sensitivity, as the H. pylori DNA was extracted from the coccoid cells of $H$. pylori in faeces containing both sensitive and resistant cells. Furthermore, our nested PCR specifically amplified the $23 \mathrm{~S}$ rRNA gene from a small amount of $H$. pylori DNA compared with the number of other bacteria in faeces. The data shown here may explain the highly sensitive detection rate in mixed infections.

In the case of mixed infections, CAM-resistant $H$. pylori may be selected using therapy including CAM, which consequently results in failure of the therapy. Although there have been several reports of mixed infections, the influence of mixed infections on the results of eradication 
therapy has not been well studied. In this study, we evaluated the influence of mixed infections in patients treated using an LAC regimen, which is the regimen used most frequently in Japan (Asaka et al., 2001). We found that the proportion of patients with a mutation in the $23 \mathrm{~S}$ rRNA gene (including mixed type) was $66.6 \%$ of patients who had been treated unsuccessfully. Recently, it has been reported that $16.4 \%$ of treatment failures showed mixed infections with antibiotic-susceptible and -resistant $H$. pylori (Kim et al., 2006). The data suggest that the existence of both CAM-resistant and -susceptible $H$. pylori may be the reason for therapy failure.

Moreover, CAM-susceptible H. pylori was detected in $33.3 \%$ of patients treated unsuccessfully using the LAC regimen. It has been reported that single nucleotide polymorphisms of cytochrome $\mathrm{P} 4502 \mathrm{C} 19$ are significantly related to eradication rates of $H$. pylori by triple therapy as well as susceptibility to CAM (Furuta et al., 2001). Although single nucleotide polymorphism analysis was not performed in this study, such polymorphisms may be the reason for the failure of therapy in these patients.

In conclusion, we have developed a method for the detection of CAM-resistant $H$. pylori from faeces, including mixed infection with CAM-susceptible and -resistant $H$. pylori. Use of this method showed that mixed infections of resistant and susceptible $H$. pylori were prevalent. Therefore, as mixed infections are common and may be the reason for unsuccessful therapy, an accurate test for the presence of CAM-resistant $H$. pylori is necessary for successful eradication therapy.

\section{ACKNOWLEDGEMENTS}

We wish to thank T. Yamaguchi, H. Kijima and R. Tamura for their technical assistance. This work was supported by a Matching Fund Subsidy for Private Universities provided by the Ministry of Education, Science, Sports and Culture, Japan.

\section{REFERENCES}

Akiyama, H., Watanabe, T., Wakabayashi, K., Nakade, S., Yasui, S., Sakata, K., Chiba, R., Spiegelhalter, F., Hino, A. \& Maitani, T. (2005). Quantitative detection system for maize sample containing combined-trait genetically modified maize. Anal Chem 77, 7421-7428.

Alarcon, T., Vega, A. E., Domingo, D., Martinez, M. J. \& Lopez-Brea, M. (2003). Clarithromycin resistance among Helicobacter pylori strains isolated from children: prevalence and study of mechanism of resistance by PCR-restriction fragment length polymorphism analysis. J Clin Microbiol 41, 486-499.

Asaka, M., Satoh, K., Sugano, K., Sugiyama, T., Takahashi, S., Fukuda, Y., Ota, H., Murakami, K., Kimura, K. \& Shimoyama, T. (2001). Guidelines in the management of Helicobacter pylori infection in Japan. Helicobacter 6, 177-186.

Booka, M., Okuda, M., Shin, K., Miyashiro, E., Hayashi, H., Yamauchi, K., Tamura, Y. \& Yoshikawa, N. (2005). Polymerase chain reactionrestriction fragment length polymorphism analysis of clarithromycinresistant Helicobacter pylori infection in children using stool sample. Helicobacter 10, 205-213.
CLSI (2002). Performance Standards for Antimicrobial Susceptibility Testing: Twelfth Informational Supplement. Wayne, PA: Clinical and Laboratory Standards Institute.

Fontana, C., Favaro, M., Minelli, S., Criscuolo, A. A., Pietroiusti, A., Galante, A. \& Favalli, C. (2002). New site of modification of $23 \mathrm{~S}$ rRNA associated with clarithromycin resistance of Helicobacter pylori clinical isolates. Antimicrob Agents Chemother 46, 3765-3769.

Fontana, C., Favaro, M., Pietroiusti, A., Pistoia, E. S., Galante, A. \& Favalli, C. (2003). Detection of clarithromycin-resistant Helicobacter pylori in stool samples. J Clin Microbiol 41, 3636-3640.

Furuta, T., Shirai, N., Takashima, M., Xiao, F., Hanai, H., Sugimura, H., Ohashi, K., Ishizaki, T. \& Kaneko, E. (2001). Effect of genotypic differences in CYP2C19 on cure rates for Helicobacter pylori infection by triple therapy with a proton pump inhibitor, amoxicillin, and clarithromycin. Clin Pharmacol Ther 69, 158-168.

Goodwin, C. S., Blincow, E. D., Warren, J. R., Waters, T. E., Sanderson, C. R. \& Easton, L. (1985). Evaluation of cultural techniques for isolating Campylobacter pyloridis from endoscopic biopsies of gastric mucosa. J Clin Pathol 38, 1127-1131.

Graham, D. Y., Klein, P. D., Evans, D. J., Jr, Evans, D. G., Alpert, L. C., Opekun, A. R. \& Boutton, T. W. (1987). Campylobacter pylori detected noninvasively by the ${ }^{13} \mathrm{C}$-urea breath test. Lancet $\mathbf{i}, 1174-1177$.

Hoshiya, S., Watanabe, K., Tokunaga, K., Tanaka, A., Ninomiya, H., Shingaki, M., Itoh, T., Saito, S., Ishida, H. \& Takahashi, S. (2000). Relationship between eradication therapy and clarithromycin-resistant Helicobacter pylori in Japan. J Gastroenterol 35, 10-14.

Ito, M., Tanaka, S., Kim, S., Tahara, K., Kawamura, Y., Sumii, M., Takehara, Y., Hayashi, K., Okamoto, E. \& other authors (2005). A combination of the Helicobacter pylori stool antigen test and urea breath test is useful for clinical evaluation of eradication therapy: a multicenter study. J Gastroenterol Hepatol 20, 1241-1245.

Kato, M., Yamaoka, Y., Kim, J. J., Reddy, R., Asaka, M., Kashima, K., Osato, M. S., El-Zaatari, F. A., Graham, D. Y. \& Kwon, D. H. (2000). Regional differences in metronidazole resistance and increasing clarithromycin resistance among Helicobacter pylori isolates from Japan. Antimicrob Agents Chemother 44, 2214-2216.

Khan, R., Nahar, S., Sultana, J., Ahmad, M. M. \& Rahman, M. (2004). T2182C mutation in 23S rRNA is associated with clarithromycin resistance in Helicobacter pylori isolates obtained in Bangladesh. Antimicrob Agents Chemother 48, 3567-3569.

Kim, J. M., Kim, J. S., Kim, N., Kim, S. G., Jung, H. C. \& Song, I. S. (2006). Comparison of primary and secondary antimicrobial minimum inhibitory concentrations for Helicobacter pylori isolated from Korean patients. Int J Antimicrob Agents 28, 6-13.

Kuipers, E. J. (1997). Helicobacter pylori and the risk and management of associated diseases: gastritis, ulcer disease, atrophic gastritis and gastric cancer. Aliment Pharmacol Ther 11 (Suppl. 1), 71-88.

Kusters, J. G., Gerrits, M. M., Van Strijp, J. A. \& VandenbrouckeGrauls, C. M. (1997). Coccoid forms of Helicobacter pylori are the morphologic manifestation of cell death. Infect Immun 65, 3672-3679.

Kusters, J. G., van Vliet, A. H. \& Kuipers, E. J. (2006). Pathogenesis of Helicobacter pylori infection. Clin Microbiol Rev 19, 449-490.

Leodolter, A., Vaira, D., Bazzoli, F., Schutze, K., Hirschl, A., Megraud, F. \& Malfertheiner, P. (2003). European multicentre validation trial of two new non-invasive tests for the detection of Helicobacter pylori antibodies: urine-based ELISA and rapid urine test. Aliment Pharmacol Ther 18, 927-931.

Leong, R. W. \& Sung, J. J. (2002). Helicobacter species and hepatobiliary diseases. Aliment Pharmacol Ther 16, 1037-1045.

Malfertheiner, P., Megraud, F., O'Morain, C., Hungin, A. P., Jones, R., Axon, A., Graham, D. Y. \& Tytgat, G. (2002). Current concepts in the 
management of Helicobacter pylori infection - the Maastricht 2-2000 Consensus Report. Aliment Pharmacol Ther 16, 167-180.

Matsuki, T., Watanabe, K., Fujimoto, J., Kado, Y., Takada, T., Matsumoto, K. \& Tanaka, R. (2004). Quantitative PCR with $16 \mathrm{~S}$ rRNA-gene-targeted species-specific primers for analysis of human intestinal bifidobacteria. Appl Environ Microbiol 70, 167-173.

McOrist, A. L., Jackson, M. \& Bird, A. R. (2002). A comparison of five methods for extraction of bacterial DNA from human faecal samples. J Microbiol Methods 50, 131-139.

Monteiro, L., Gras, N., Vidal, R., Cabrita, J. \& Megraud, F. (2001). Detection of Helicobacter pylori DNA in human feces by PCR: DNA stability and removal of inhibitors. J Microbiol Methods 45, 89-94.

Morris, J. M., Reasonover, A. L., Bruce, M. G., Bruden, D. L., McMahon, B. J., Sacco, F. D., Berg, D. E. \& Parkinson, A. J. (2005). Evaluation of seaFAST, a rapid fluorescent in situ hybridization test, for detection of Helicobacter pylori and resistance to clarithromycin in paraffin-embedded biopsy sections. J Clin Microbiol 43, 3494-3496.

Nurgalieva, Z. Z., Opekun, A. R. \& Graham, D. Y. (2006). Problem of distinguishing false-positive tests from acute or transient Helicobacter pylori infections. Helicobacter 11, 69-74.

Prokhorenko, I. A., Malakhov, A. D., Kozlova, A. A., Momynaliev, K., Govorun, V. M. \& Korshun, V. A. (2006). Phenylethynylpyrene-labeled oligonucleotide probes for excimer fluorescence SNP analysis of $23 \mathrm{~S}$ rRNA gene in clarithromycin-resistant Helicobacter pylori strains. Mutat Res 599, 144-151.

Rimbara, E., Noguchi, N., Tanabe, M., Kawai, T., Matsumoto, Y. \& Sasatsu, M. (2005a). Susceptibilities to clarithromycin, amoxycillin and metronidazole of Helicobacter pylori isolates from the antrum and corpus in Tokyo, Japan, 1995-2001. Clin Microbiol Infect 11, 307-311.

Rimbara, E., Noguchi, N., Yamaguchi, T., Narui, K., Kawai, T. \& Sasatsu, M. (2005b). Development of a highly sensitive method for detection of clarithromycin-resistant Helicobacter pylori from human feces. Curr Microbiol 51, 1-5.

Schabereiter-Gurtner, C., Hirschl, A. M., Dragosics, B., Hufnagl, P., Puz, S., Kovach, Z., Rotter, M. \& Makristathis, A. (2004). Novel realtime PCR assay for detection of Helicobacter pylori infection and simultaneous clarithromycin susceptibility testing of stool and biopsy specimens. J Clin Microbiol 42, 4512-4518.

Shuber, A. P., Ascano, J. J., Boynton, K. A., Mitchell, A., Frierson, H. F., Jr, El-Rifai, W. \& Powell, S. M. (2002). Accurate, noninvasive detection of Helicobacter pylori DNA from stool samples: potential usefulness for monitoring treatment. J Clin Microbiol 40, 262-264.

Thomas, J. E., Gibson, G. R., Darboe, M. K., Dale, A. \& Weaver, L. T. (1992). Isolation of Helicobacter pylori from human faeces. Lancet 340, 1194-1195.

Toracchio, S., Aceto, G. M., Mariani-Costantini, R., Battista, P. \& Marzio, L. (2004). Identification of a novel mutation affecting domain $\mathrm{V}$ of the $23 \mathrm{~S}$ rRNA gene in Helicobacter pylori. Helicobacter 9, 396-399.

Vaira, D., Malfertheiner, P., Megraud, F., Axon, A. T., Deltenre, M., Hirschl, A. M., Gasbarrini, G., O'Morain, C., Garcia, J. M. \& other authors (1999). Diagnosis of Helicobacter pylori infection with a new non-invasive antigen-based assay. HpSA European study group. Lancet 354, 30-33.

van Doorn, L. J., Glupczynski, Y., Kusters, J. G., Mégraud, F., Midolo, P., Maggi-Solcà, N., Queiroz, D. M., Nouhan, N., Stet, E. \& Quint, W. G. (2001). Accurate prediction of macrolide resistance in Helicobacter pylori by a PCR line probe assay for detection of mutations in the $23 \mathrm{~S}$ rRNA gene: multicenter validation study. Antimicrob Agents Chemother 45, 1500-1504.

Wong, B. C., Wang, W. H., Berg, D. E., Fung, F. M., Wong, K. W., Wong, W. M., Lai, K. C., Cho, C. H., Hui, W. M. \& Lam, S. K. (2001). High prevalence of mixed infections by Helicobacter pylori in Hong Kong: metronidazole sensitivity and overall genotype. Aliment Pharmacol Ther 15, 493-503. 